

\title{
Entoepidemiology of Chagas disease in the Western region of the State of São Paulo from 2004 to 2008, and cytogenetic analysis in Rhodnius neglectus (Hemiptera, Triatominae)
}

\author{
K.C.C. Alevi ${ }^{1}$, L.A.C Rodas ${ }^{2}$, E. Tartarotti ${ }^{3}$, M.T.V. Azeredo-Oliveira ${ }^{1}$ and \\ M.M. Guirado ${ }^{4}$ \\ ${ }^{1}$ Laboratório de Biologia Celular, Departamento de Biologia, \\ Instituto de Biociências, Letras e Ciências Exatas, Universidade Estadual \\ Paulista "Júlio de Mesquita Filho", São José do Rio Preto, SP, Brasil \\ ${ }^{2}$ Superintendência de Controle de Endemias, Araçatuba, SP, Brasil \\ ${ }^{3}$ Centro de Ciências Biológicas e da Saúde, \\ Universidade Federal de Mato Grosso do Sul, Campo Grande, MS, Brasil \\ ${ }^{4}$ Laboratório de Vetores, Superintendência de Controle de Endemias, \\ São José do Rio Preto, SP, Brasil \\ Corresponding author: K.C.C. Alevi \\ E-mail: kaiochaboli@hotmail.com
}

Genet. Mol. Res. 14 (2): 5775-5784 (2015)

Received July 11, 2014

Accepted March 5, 2015

Published May 29, 2015

DOI http://dx.doi.org/10.4238/2015.May.29.9

ABSTRACT. To complement the epidemiological data and assist in the prophylaxis of Chagas disease in the State of São Paulo, we examined entomological lifting conducted in 40 municipalities of the Western region of the state from 2004 to 2008, highlighted the main vector species in this region, and reanalyzed the cytogenetic characteristics of Rhodnius neglectus from 3 different Brazilian states (Formoso/GO, Frutal/MG, Guaíra/SP, and Pitangueiras/SP). The municipalities of Castilho and Santo Antônio do Acaranguá registered the highest relative amounts of notifications. The main species notified 
in Western São Paulo were Triatoma sordida and $R$. neglectus. We collected a large number of T. sordida in 2005 and noted the absence of notification of infected insects in 2008. We observed no variation in chromosomal characteristics of $R$. neglectus of different states. These data are complementary to the survey presented from 1990 to 1999 , as the vector species were the same (T. sordida and R. neglectus), with emphasis on $T$. sordida. We corroborate the future colonization domiciliary initially proposed for $T$. sordida in the region and underscore the importance of vector control programs in the prophylaxis of Chagas disease. Furthermore, we observed that the populations of $R$. neglectus in Brazil showed no intraspecific variation and we corroborated the chromosomal patterns originally described. These data are important for understanding the evolution of these hematophagous insects, which are vectors of Chagas disease.

Key words: Entoepidemiological lifting; Heterochromatin; Holocentric chromosome

\section{INTRODUCTION}

Triatomines belong to the Hemiptera order, Heteroptera suborder, Reduviidae family, and Triatominae subfamily (Lent and Wygodzinsky, 1979). The Triatominae subfamily is composed of 148 species distributed in 18 genera and 6 tribes (Tartarotti et al., 2006; AbadFranch et al., 2013; Alevi et al., 2013a; Poinar, 2013). All triatomine species are hematophagous and potential vectors of Chagas disease. During the repast, these insects can become infected with the etiologic agent of Chagas disease Trypanosoma cruzi, a protozoan that can be transferred between hosts by these vectors (Noireau et al., 2009).

This disease is regarded as the second most endemic disease in Latin America. Approximately 8 million people are infected with $T$. cruzi worldwide, and approximately 2.5 million people are infected in Brazil (Neto and Pasternak, 2009; WHO, 2013). Because there is no specific treatment for Chagas disease, control of vector populations is the main method used for minimizing the incidence of this disease, which has recently been referred to as "the new acquired immunodeficiency syndrome (AIDS) of the Americas" (Hotez et al., 2012).

Currently, 65 triatomine species have been identified in Brazil (Gardim et al., 2014) and were found to be involved in the transmission of Chagas disease, highlighting Triatoma infestans, Panstrongylus megistus, Triatoma brasiliensis, Triatoma sordida, Triatoma pseudomaculata, and Rhodnius neglectus (Dias and Schofield, 1998; Silistino-Souza et al., 2013). After the International Certification of Elimination of Chagas Disease Transmission by $T$. infestans, conferred by the Pan American Health Organization, other species were found to be involved in the transmission of Chagas disease in the State of São Paulo; for T. sordida, P. megistus, and $R$. neglectus, recent entomological lifting showed a high incidence of these hemipterans inhabiting peri and intradomiciliary regions and, in some cases, were infected with T. cruzi (Wanderley et al., 2007; Silva et al., 2011; Silistino-Souza et al., 2013).

$R$. neglectus is important in the enzootic transmission of T. cruzi and T. rangeli (Gurgel-Gonçalves et al., 2004; Gurgel-Gonçalves and Cuba, 2009), and was recently found by different authors to inhabit palm trees in urban areas (Carvalho et al., 2014; Rodrigues et al., 
2014). These insects have been observed in 13 Brazilian states, including Bahia, Distrito Federal, Goiás, Maranhão, Minas Gerais, Mato Grosso do Sul, Mato Grosso, Pernambuco, Piauí, Paraná, Rio de Janeiro, São Paulo, and Tocantins (Gurguel-Gonçalves et al., 2012). In Minas Gerais, São Paulo, and Goiás, evidence exists of colony formation in domiciliary regions (Barretto et al., 1968; Silva et al., 1999; de Oliveira and Silva, 2007; Silistino-Souza et al., 2013).

Cytogenetic analysis has shown to be an important cytotaxonomic tool for the differentiation of triatomines (Alevi et al., 2012a,b; 2013b, c, d, e; 2014). Barth (1956) described the karyotype of $R$. neglectus as $2 \mathrm{n}=22(20 \mathrm{~A}+\mathrm{XY})$. The study also described some characteristics of the chromosomes of this vector, such as the size of the autosomes ( 3 pairs large +6 medium +1 small) and sex chromosomes (Y slightly bigger than X). Dujardin et al. (2002) described the pattern of constitutive heterochromatin of species and observed that $R$. neglectus only presented heterochromatin in the Y sex chromosome. However, Santos (2010) analyzed a population of Tocantins and reported that the species has heterochromatic blocks at the end of some autosomes.

In order to complement the epidemiological data and assist in the prophylaxis of Chagas disease in the State of São Paulo, we conducted an entomological lifting study in 40 municipalities of the Western region of the state from 2004 to 2008, highlighted the main vector species in this region, and reanalyzed the cytogenetic characteristics of $R$. neglectus in 3 different Brazilian states.

\section{MATERIAL AND METHODS}

The analysis of the triatomines fauna of the Western region of the State of São Paulo was obtained from reports of triatomines by the population received from 2004 to 2008 by the Superintendência de Controle de Endemias (SUCEN) of Araçatuba. The SUCEN of Araçatuba is responsible for monitoring the 40 counties west of São Paulo (Alto Alegre, Andradina, Araçatuba, Auriflama, Avanhandava, Barbosa, Bento de Abreu, Bilac, Birigui, Braúna, Brejo Alegre, Buritama, Castilho, Clementina, Coroados, Gabriel Monteiro, Glicério, Guaraçaí, Guararapes, Guzolândia, Ilha Solteira, Itapura, Lavínia, Lourdes, Luiziânia, Mirandópolos, Murutinga do Sul, Nova Castilho, Nova Independência, Nova Luzitânia, Penápolis, Pereira Barreto, Placatú, Rubiácea, Santo Antônio do Aracanguá, Santopolos do Aguapeí, Sud Mennuci, Suzanópolis, Turiúba, and Valparaíso) (Figure 1). The insects found in these locations were collected and sent for laboratory exams to identify possible triatomines infected by the parasite $T$. cruzi. The feeding habits of insects collected were analyzed in the Laboratory of Chagas from SUCEN, located in Mogui Guaçu, São Paulo, Brazil. Based on the notifications registered by SUCEN from 2004 to 2008 in 40 counties, we calculated the mean, median, standard deviation, minimum, and maximum of the following variables: notification, triatomines captures, and examined species captured. For comparison between municipalities, we constructed 2 graphs using the data to the scale of the standardized measure by transformation: variable frequency $\mathrm{X}$ divided by the population density of the municipality. The statistical software Minitab for Windows version 14.0 was used.

Based on information about the triatomines collected by SUCEN, we constructed 3 tables. Table 1 shows the relationship between collected specimens and infected specimens, based on the total number of insects collected in the 40 municipalities. Tables 2 and 3 show the relationship between vectors infected with the type of host based on blood found in the insect gut. After inspecting each notification site, the SUCEN performed nebulizations with insecticides.

For cytogenetics analysis, at least 10 specimens of adult male $R$. neglectus from each locality (Formoso/GO, Frutal/MG, Guaíra/SP, and Pitangueiras/SP) were analyzed cytoge- 
netically using lacto-acetic orcein (De Vaio et al., 1985, with modifications according to Alevi et al., 2012a) and C-banding (Sumner, 1972).

\section{RESULTS}

\section{Entomological lifting}

Figure 1 shows the average, minimum, and maximum of notifications from each municipality. The municipalities of Castilho and Santo Antônio do Acaranguá registered the highest relative numbers of notifications. In addition, in the municipalities of Alto Alegre, Glicério, Guaraçaí, Itapura, Muritinga do Sul, and Nova Independencia, the number of notifications was higher than in other municipalities (Figure 2).

Figure 2 shows the frequency of notifications each year in the 40 municipalities. In 2005, the greatest frequency of notifications in most municipalities was reported, particularly in Castilho and Santo Antônio do Acaranguá. Furthermore, the record of notifications generally decreased, with the exception of Itapura and Murutinga do Sul, which registered an increase number of notifications in 2007 and 2008, respectively (Figure 3).

The main species notified by SUCEN in Western São Paulo were T. sordida and $R$. neglectus. Table 1 shows that the capture of T. sordida was much more frequent than that of $R$. neglectus. Based on the specimens collected, the SUCEN conducted tests of infection by $T$. cruzi (Table 1). A large number of T. sordida was collected in 2005 and, mainly, notification of infected insects was absent in 2008.

Based on the triatomines infected shown in Table 1, the SUCEN performed blood tests to detect the host on which the contaminated insect showed hematophagy. In Triatoma sordida the presence of human blood, possum blood, rodent blood, and bird blood were notified (Table 2 ), and in R. neglectus was reported dog blood (Table 3).

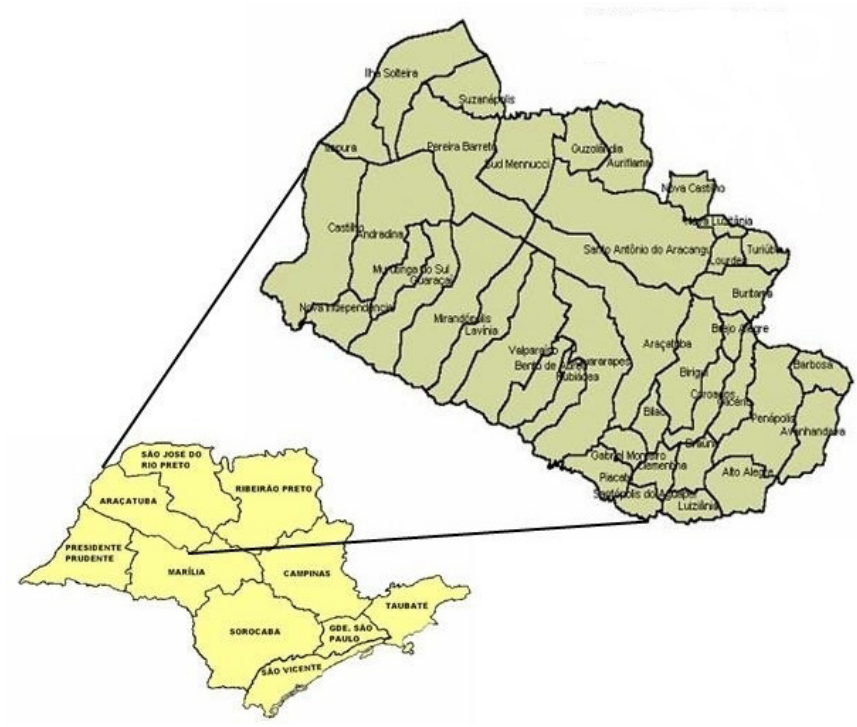

Figure 1. Forty counties of west of São Paulo monitored by Superintendência de Controle de Endemias of Araçatuba. 


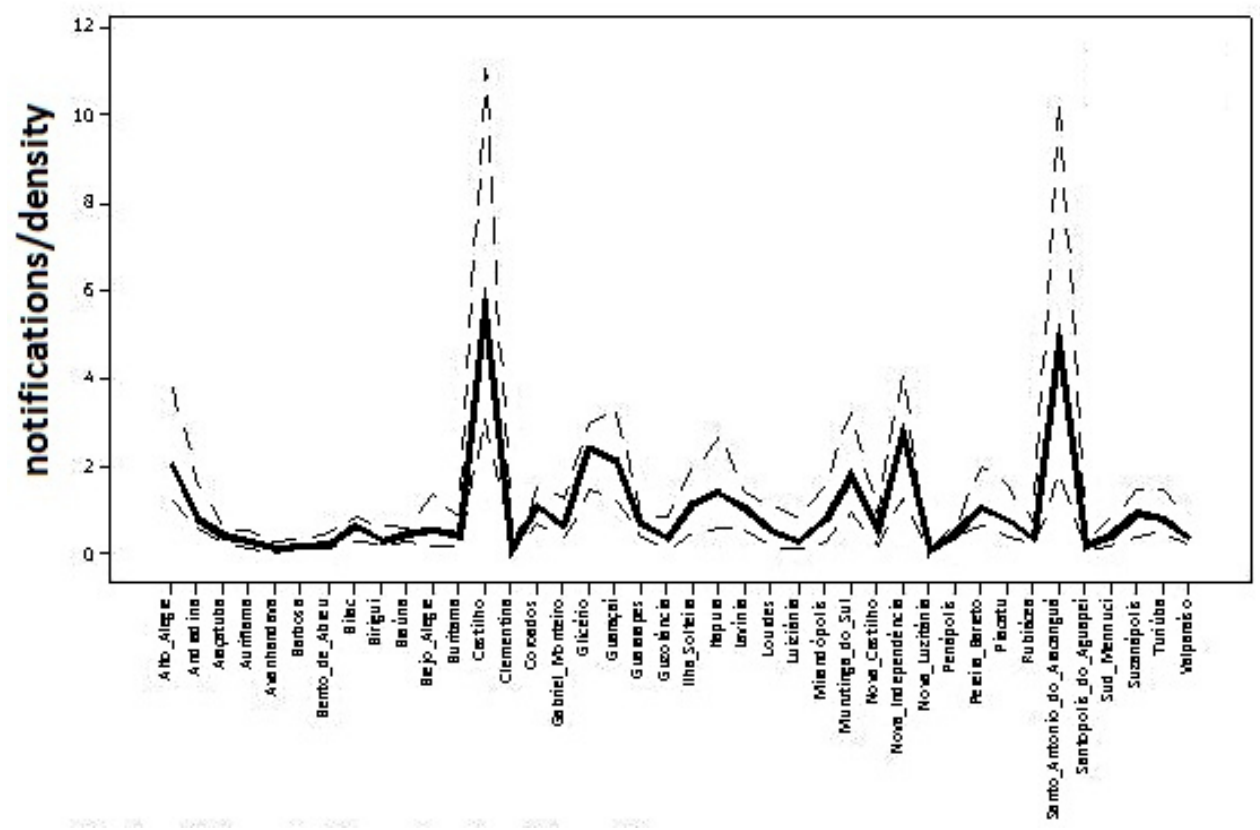

Figure 2. Average, minimum, and maximum of notifications in each municipality.

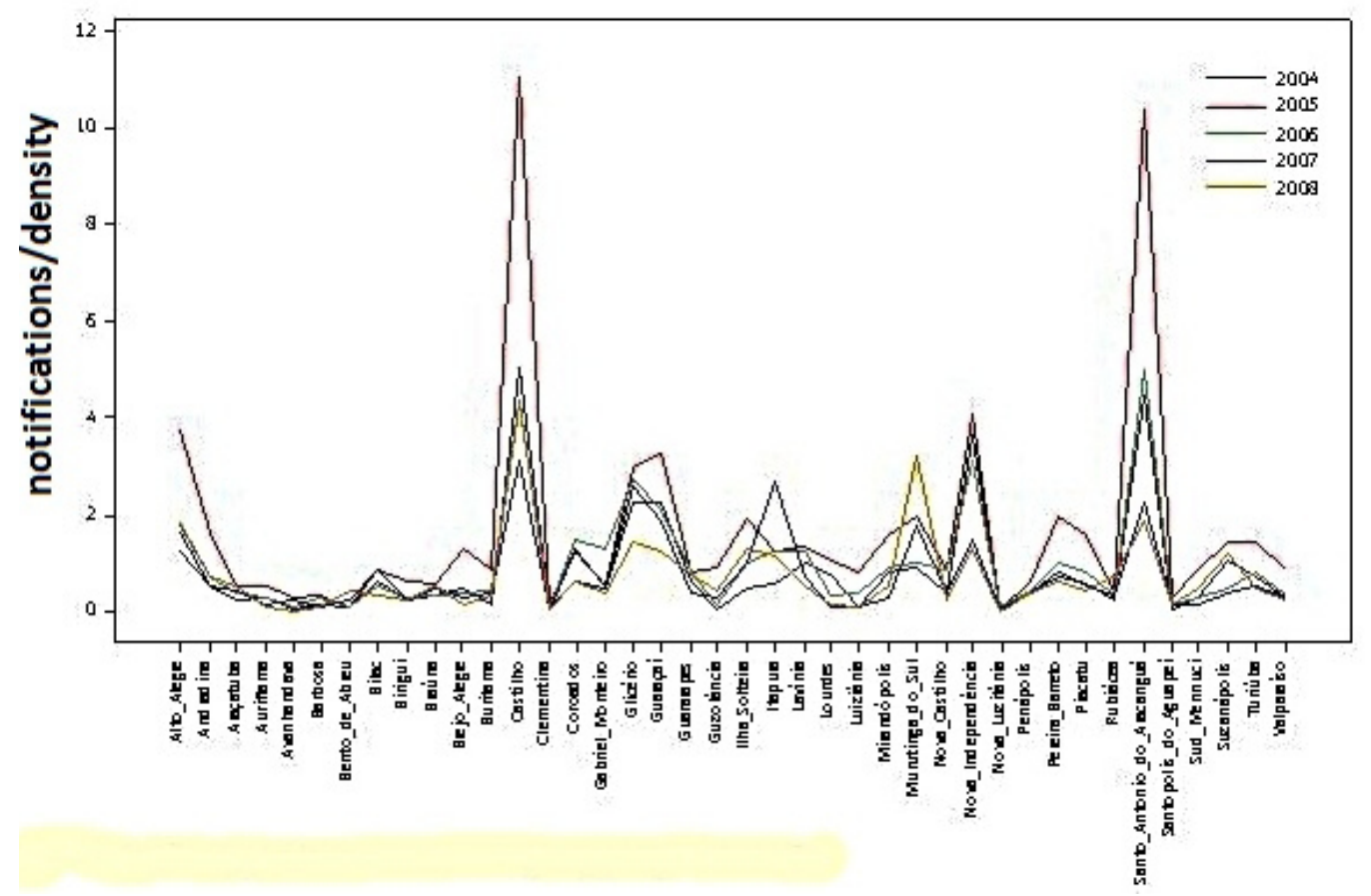

Figure 3. Notifications registered from 2004 to 2008 in 40 counties of West Paulista. 
Table 1. List of Triatoma sordida and Rhodnius neglectus samples collected and infected over 4 years in 40 municipalities of West Paulista.

\begin{tabular}{lccccc}
\hline Years & \multicolumn{3}{c}{ Triatoma sordida } & \multicolumn{2}{c}{ Rhodnius neglectus } \\
\cline { 2 - 3 } & Collected & Infected & & Collected & Infected \\
\hline 2004 & 3285 & 5 & 144 & 0 \\
2005 & 7082 & 8 & 281 & 2 \\
2006 & 3278 & 4 & 145 & 0 \\
2007 & 2247 & 0 & 195 & 0 \\
2008 & 2532 & 32 & 245 & 4 \\
Total & 18,424 & & 1010 & \\
\hline
\end{tabular}

Table 2. List of Triatoma sordida and type of host infected.

\begin{tabular}{lcccccc}
\hline Years & Infected & Human & Opossum & Rodent & Bird & Dog \\
\hline 2004 & 5 & 2 & & 2 & & None \\
2005 & 15 & 2 & 1 & 6 & $3 *$ & 1 \\
2006 & 8 & 2 & 2 & & 2 & 4 \\
2007 & 4 & 1 & & & 1 & \\
2008 & 0 & & & & & \\
\hline
\end{tabular}

*Detected in bird blood and human blood.

Table 3. List of Rhodnius neglectus infected with the kind of host.

\begin{tabular}{|c|c|c|c|c|c|c|c|}
\hline Years & Infected & Human & Opossum & Rodent & Bird & Dog & None \\
\hline 2004 & 0 & & & & & & \\
\hline 2005 & 2 & & & & & 1 & 1 \\
\hline 2006 & 2 & & & & & 1 & 1 \\
\hline 2007 & 0 & & & & & & \\
\hline 2008 & 0 & & & & & & \\
\hline
\end{tabular}

\section{Cytogenetic analysis}

Cytogenetic analysis of the chromosome number and structure of the 4 populations was identical to that described by Barth (1956) (Figure 4). However, variations in the size of chromosomes as described by Barth (1956) were very small. The heterochromatic pattern was also identical to that described by Dujardin et al. (2002) (Figure 5). As all populations showed the same characteristics, we represent the heterochromatic pattern of populations of $R$. neglectus using one images of leptotene (Figure 5A) and one of diplotene (Figure 5B). The presence of heterochromatic blocks dispersed in the nucleus during leptotene and the presence of heterochromatic blocks during chromosome condensation (diplotene) would be easily detected if they were present in the chromosomes of R. neglectus.

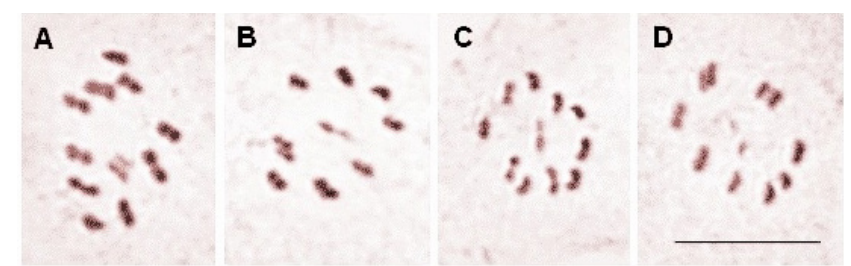

Figure 4. Meiotic metaphases of Rhodnius neglectus. A. Metaphase I of Formoso/GO. B. Metaphase II of Frutal/ MG. C. Metaphase II of Guaíra/SP. D. Metaphase II of Pitangueiras/SP. Bar: $10 \mu \mathrm{m}$. 


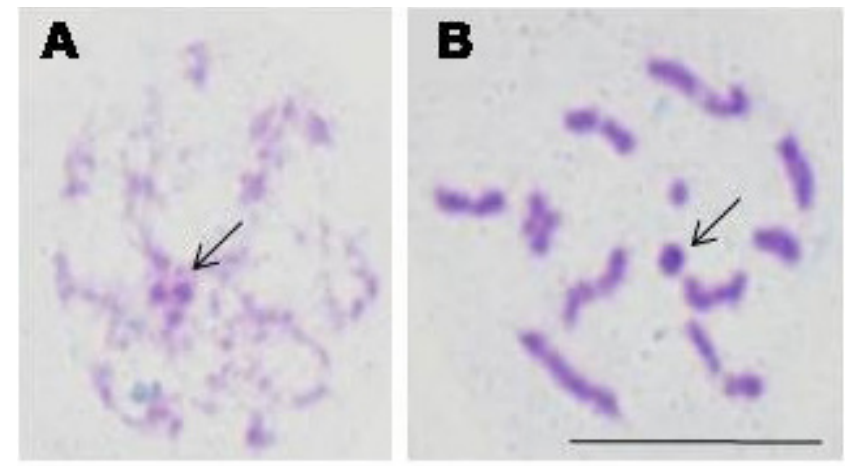

Figure 5. Stages of meiosis of Rhodnius neglectus. (A) Leptotene and (B) diplotene. Note the chromocenter (A) and sex chromosome Y (B) heterochromatics (arrows). Bar: $10 \mu \mathrm{m}$.

\section{DISCUSSION}

In 1979, Forattini et al. (1979) reported the presence of P. megistus, $T$. sordida, and $R$. neglectus in the state of São Paulo. Of the total species collected, 2280 nymphs were P. megistus, 8009 were T. sordida, and 100 were $R$. neglectus, and 19, 9, 9.4, and $2 \%$ were observed in the same household regions.

Silva et al. (2010) conducted a survey in the municipality of Potirendaba from 2004 to 2006 and observed that of the 355 exemplary triatomines collected, $97.3 \%$ were $T$. sordida and $2.7 \%$ were $R$. neglectus. All insect specimens showed negative results for T. cruzi.

Silistino-Souza et al. (2013) conducted an epidemiological study of Chagas disease in the northwest of the State of São Paulo from 2004 to 2011. The authors also observed that the most common species were $T$. sordida and R. neglectus, mainly $T$. sordida. Of the 14,583 triatomines collected, only 6 exemplars of $T$. sordida were found to be infected with $T$. cruzi, representing approximately $0.04 \%$ of the total specimens collected.

Rodrigues et al. (2009) reported the presence of $R$. neglectus infestation in buildings in Araçatuba from 2004 to 2007. Twenty nymphs were collected in one of the rooms on the 10 th floor of a building. Fortunately, all were negative for $T$. cruzi, as 3 nymphs were detected with human blood. In 2007, the authors studied the dispersion of $R$. neglectus in Araçatuba city and observed that of the 34 palm trees examined, 25 were infected with $R$. neglectus, allowing for the collection of 357 species. It is thought that palm trees function as bridges to infestation of buildings by $R$. neglectus.

Silva et al. (2003) surveyed 21 municipalities in the region of Araçatuba from 1990 to 1999. In 20 municipalities analyzed, the predominant species was T. sordida. This species was detected mainly in the peridomicile regions, which may result in future colonization of domicile regions (Diotaiuti et al., 1994; Dias and Schofield, 1998). In the 2004-2008 survey, the main species in the Western region of the State of São Paulo also were T. sordida and $R$. neglectus. Of the 19,434 specimens collected, approximately $95 \%$ were also $T$. sordida. In the 40 municipalities analyzed, the vector in the domiciliary region was absent. According to Silistino-Souza et al. (2013), populations of T. sordida of Brazil may show from cryptic speciation, allowing for better adaptation of this vector to different environments.

Of the specimens of $T$. sordida and R. neglectus collected, approximately 0.17 and $0.4 \%$ were infected with $T$. cruzi. Although these percentages are low, and in 2008 no speci- 
mens collected were found to be infected by the protozoan, it is important to continue the supervision of vector control programs as a prophylactic measure against Chagas disease, as the vectors are present in the State São Paulo.

In 32 exemplars of $T$. sordida contaminated by $T$. cruzi were detected mainly human, opossum and rodent, and bird blood. This test allows analyzing the organisms that are functioning as vertebrate hosts and possibly as reservoirs for $T$. cruzi. Birds are refractory and resistant to infection by $T$. cruzi, making it difficult for these vertebrates to operate as reservoirs of Chagas disease (Kierszenbaum et al., 1976).

The elimination of $T$. infestans has vacated new niches, and species of secondary importance in the transmission of Chagas disease, such as R. neglectus, were considered sylvatic and passed to domiciliary regions. The domiciliation process of triatomines can lead to chromosomal alterations, as observed by Panzera et al. (2004) to T. infestans. However, analysis of the 4 populations of $R$. neglectus revealed that these organisms had no intraspecific variation. Although we do not discard the possibility of polymorphism, the holocentric nature of chromosomes of the triatomines and small size of the chromosomes in the genus Rhodnius may have led to an incorrect interpretation of the heterochromatic pattern in the population of $R$. neglectus of Tocantins.

We surveyed the entoepidemiological data regarding Chagas disease in the Western region of the State of São Paulo from 2004 to 2008. These data are complementary to the survey conducted from 1990 to 1999, as the vector species were the same (T. sordida and $R$. neglectus). We corroborate the possibility of future colonization of domiciliary regions and we underscore the importance of vector control programs for the prophylaxis of Chagas disease. Furthermore, the populations of $R$. neglectus in Brazil showed no intraspecific variation and we corroborate the chromosomal patterns originally described by Barth (1956) and Dujardin et al. (2002) for the species $R$. neglectus. These data are important for understanding the evolution of these hematophagous insects, which are vectors of Chagas disease.

\section{ACKNOWLEDGMENTS}

Research supported by Fundação de Amparo à Pesquisa do Estado de São Paulo (Process \#2005/55804-0 and \#2013/19764-0) and Conselho Nacional de Desenvolvimento Científico e Tecnológico.

\section{REFERENCES}

Abad-Franch F, Pavan MG, Jaramillo-O N, Palomeque FS, et al. (2013). Rhodnius barretti, a new species of Triatominae (Hemiptera: Reduviidae) from Western Amazonia. Mem. Inst. Oswaldo Cruz 108: 92-99.

Alevi KCC, Mendonça PP, Suci M, Pereira NP, et al. (2012a). Karyotype of Triatoma melanocephala Neiva and Pinto (1923). Does this species fit in the Brasiliensis subcomplex? Infect. Genet. Evol. 12: 1652-1653.

Alevi KCC, Mendonça PP, Pereira NP, Rosa JA, et al. (2012b). Karyotype and spermatogenesis in Triatoma lenti (Hemiptera: Triatominae), a potential Chagas vector. Genet. Mol. Res. 11: 4278-4284.

Alevi KCC, Rosa JA and Azeredo Oliveira MTV (2013a). Mini review: karyotypic survey in Triatominae subfamily (Hemiptera, Heteroptera). Entomol. Ornithol. Herpetol. 2: 106.

Alevi KCC, Mendonça PP, Pereira NP, Rosa JA, et al. (2013b). Spermatogenesis in Triatoma melanocephala (Hemiptera: Triatominae). Genet. Mol. Res. 12: 4944-4947.

Alevi KCC, Mendonça PP, Pereira NP, Rosa JA, et al. (2013c). Heteropyknotic filament in spermatids of Triatoma melanocephala and T. vitticeps (Hemiptera, Triatominae). Inv. Rep. Dev. 58: 9-12.

Alevi KCC, Mendonça PP, Pereira NP, Guerra AL, et al. (2013d). Distribution of constitutive heterochromatin in two species of triatomines: Triatoma lenti Sherlock and Serafim (1967) and Triatoma sherlocki Papa, Jurberg, Carcavallo, 
Cerqueira \& Barata (2002). Infect. Genet. Evol. 13: 301-303.

Alevi KCC, Mendonça PP, Pereira NP, Fernandes AL, et al. (2013e). Analysis of spermiogenesis like a tool in the study of the triatomines of the Brasiliensis subcomplex. C. R. Biol. 336: 46-50.

Alevi KCC, Rosa JA and Azeredo-Oliveira MTV (2014). Spermatogenesis in Triatoma melanica Neiva and Lent, 1941 (Hemiptera, Triatominae). J. Vector Ecol. 39: 231-233.

Barretto MP, Siqueira AF, Ferriolli FF and Carvalheiro JR (1968). Wild reservoirs and vectors of Trypanosoma cruzi. 23. Colonization of Rodnius neglectus Lent, 1954 in man-made dwellings (Hemiptera, Reduviidae). Rev. Inst. Med. Trop. 10: 163-170.

Barth R (1956). Estudos anatômicos e histológicos sobre a subfamília Triatominae (Heteroptera, Reduviidae). VI parte: Estudo comparativo sobre a espermiocitogênese das espécies mais importantes. Mem. Inst. Oswaldo Cruz 54: 599-616.

Carvalho DB, Almeida CE, Rocha CS, Gardim S, et al. (2014). A novel association between Rhodnius neglectus and the Livistona australis palm tree in an urban center foreshadowing the risk of Chagas disease transmission by vectorial invasion in Monte Alto City, São Paulo, Brazil. Acta Trop. 130: 35-38.

de Oliveira AWS and Silva IG (2007). Geographical distribution and indicators entomologic of sinantropic triatomes captured in the State of Gojiás. Rev. Soc. Bras. Med. Trop. 40: 204-208.

De Vaio ES, Grucci B, Castagnino AM, Franca ME, et al. (1985). Meiotic differences between three triatomine species (Hemiptera, Reduviidae). Genetica 67: 185-191.

Dias JC and Schofield CJ (1998). The control of the transmission by transfusion of Chagas' disease in the Southern Cone Initiative. Rev. Soc. Bras. Med. Trop. 31: 373-383.

Diotaiuti L, Ribeiro de Paula O, Falcão PL and Dias JC (1994). Evaluation of the Chagas disease vector control program in Minas Gerais, Brazil, with special reference to Triatoma sordida. Bull. Pan. Am. Health Organ. 28: 211-219.

Dujardin JP, Schofield CJ and Panzera F (2002). Los vectores de la enfermedad de Chagas, Académie Royale des Sciences D’Outre-Mer, Bruxelles.

Forattini OP, Ferreira OA, Rocha e Silva EO and Rabello EX (1979). Ecological aspects of South American trypanosomiasis. XV. Development, variation and permanence of Triatoma sordida, Panstrongylus megistus and Rhodnius neglectus in artificial ecotopes. Rev. Saude Publ. 13: 220-234.

Gardim S, Almeida CE, Takiya DM, Oliveira J, et al. (2014). Multiple mitochondrial genes of some sylvatic Brazilian Triatoma: Non-monophyly of the T. brasiliensis subcomplex and the need for a generic revision in the Triatomini. Infect. Genet. Evol. 23: 74-79.

Gurgel-Gonçalves R and Cuba CA (2009). Predicting the potential geographical distribution of Rhodnius neglectus (Hemiptera, Reduviidae) based on ecological niche modeling. J. Med. Entomol. 46: 952-960.

Gurgel-Gonçalves R, Ramalho ED, Duarte MA, Palma ART, et al. (2004). Enzootic transmission of Trypanosoma cruzi and Trypanosoma rangeli in Federal District of Brazil. Rev. Inst. Med. Trop. 46: 323-330.

Gurgel-Gonçalves R, Galvão C, Costa J and Peterson AT (2012). Geographic distribution of Chagas disease vectors in Brazil based on ecological niche modeling. J. Trop. Med. 2012: 15.

Hotez PJ, Dumonteil E, Woc-Colburn L, Serpa JA, et al. (2012). Chagas Disease: "The New HIV/AIDS of the Americas". PLOS Negl. Trop. Dis. 6: e1498.

Kierszenbaum F, Ivanyi J and Budzko DB (1976). Mechanisms of natural resistance to trypanosomal infection. Role of complement in avian resistance to Trypanosoma cruzi infection. Immunology 30: 1-6.

Lent H and Wygodzinsky P (1979). Revision of the Triatominae (Hemiptera: Reduviidae) and their significance as vector of Chagas's disease. Bull. Am. Mus. Nat. Hist. 163: 123-520.

Neto VA and Pasternak J (2009). Chagas disease centenary. Rev. Saude Publ. 43: 381-382.

Noireau F, Diosque P and Jansen AM (2009). Trypanosoma cruzi: adaptation to its vectors and its hosts. Vet. Res. 40: 26.

Panzera F, Dujardin JP, Nicolini P, Caraccio MN, et al. (2004). Genomic changes of Chagas disease vector, South America. Emerg. Infect. Dis. 10: 438-446.

Poinar Jr G (2013). Panstrongylus hispaniolae sp. n. (Hemiptera: Reduviidae: Triatominae), a new fossil triatomine in Dominican amber, with evidence of gut flagellates. Palaeodiver. 6: 1-8.

Rodrigues VLCC, Silva RA, Wanderley DMV, Carvalho ME, et al. (2009). Detecção de triatomíneos da espécie Rhodnius neglectus em área urbana de municípios da região de Araçatuba. Bol. Epidemiol. Paulista 6: 20-23.

Rodrigues VLCC, Pauliquevis Jr C, Silva RA, Wanderley DMV, et al. (2014). Colonization of palm trees by Rhodnius neglectus and household and invasion in urban area, Araçatuba, São Paulo State, Brazil. Rev. Inst. Med. Trop. 56: 213-218.

Santos SM (2010). Estudo citogenético de quatro espécies de triatomíneos (Hemiptera: Reduviidae). Doctoral thesis, Universidade Federal de Viçosa, Minas Gerais, Brasil.

Silistino-Souza R, Alevi KCC, Castro NFC, Freitas MN, et al. (2013). Entoepidemiology of Chagas disease in northwest São Paulo and cytogenetic analysis of its main vector, Triatoma sordida (Hemiptera: Triatominae). Genet. Mol. Res. 12: 5810-5819. 
Silva RA, Bonifácio PR and Wanderley DMV (1999). Doença de Chagas no estado de São Paulo: comparação entre pesquisa ativa de triatomíneos em domicílios e notificação de sua presença pela população em área sob vigilância entomológica. Rev. Inst. Med. Trop. 32: 653-659.

Silva RA, Rodrigues VLCC, Carvalho ME and Pauliquévis Jr. C (2003). Chagas Disease Control Program in the State of São Paulo: persistence of high triatomine infestation rates in some localities during the 1990s. Cad. Saúde Públ. 19: $965-971$.

Silva RA, Scandar SAS, Rodrigues VLCC and Júnior RPC (2010). Cuidados do domiciílio pela população em área infestada por Triatoma sordida. Rev. Baiana Saúde Publ. 34: 267-278.

Silva RA, Mercado TC, Barbosa GL, Rodrigues VLCC, et al. (2011). Current situation of entomological surveillance of Chagas disease in the State of São Paulo. Bol. Epidemiol. Paulista 8: 4-13.

Sumner AT (1972). A simple technique for demonstrating centromeric heterochromatin. Exp. Cell Res. 75: 304-306.

Tartarotti E, Azeredo-Oliveira MTV and Ceron CR (2006). Phylogenetic approach to the study of triatomines (Triatominae, Heteroptera). Braz. J. Biol. 66: 703-708.

Wanderley DMV, Silva RA, Carvalho ME and Barbosa GL (2007). Doença de Chagas: a vigilância entomológica no Estado de São Paulo. Bol. Epidemiol. Paulista 38: 8-12.

World Health Organization (WHO) (2013). Chagas disease. American trypanosomiasis. http://www.who.int/mediacentre/ factsheets/fs340/en/, accessed June 23, 2014. 